\title{
Florid cemento-osseous dysplasia and osteomyelitis: A case report of a simultaneous presentation
}

\author{
Displasia cemento-óssea florida e osteomielite: \\ relato de caso de uma apresentação simultânea
}

\begin{abstract}
Purpose: To report a case of florid cemento-osseous dysplasia (FCOD) and chronic diffuse sclerosing osteomyelitis (CDSO) in a simultaneous presentation, emphasizing the significance of differential diagnosis and appropriate management of these conditions.

Case description: A female, 69 years old, black patient had a complaint of itching and pain in posterior left mandibular region. The patient had a yellowish hard mass throughout all quadrants of the jaws. A panoramic radiograph showed a lobular, diffuse and irregular radiopaque lesion. Based on clinical and histopathological findings, the diagnosis was FCOD associated with secondary osteomyelitis.

Conclusion: This report reinforces the need of accurate assessment of clinical, radiographic and histopathological aspects for the diagnosis and correct selection of treatment in cases of combined lesions.
\end{abstract}

Key words: Fluorid cemento-osseous dysplasia; osteomyelitis

\section{Resumo}

Objetivo: relatar um caso de displasia cemento-óssea florida (DCOF) e osteomielite esclerosante difusa crônica (OEDC) em uma apresentação simultânea, enfatizando a importância do diagnóstico diferencial e adequado manejo dessas condições.

Descrição do caso: Uma paciente do sexo feminino, 69 anos de idade, de cor negra, tinha uma queixa de dor e coceira na região esquerda da mandíbula. A paciente apresentava uma massa dura amarelada envolvendo todos os quadrantes dos maxilares. Foi obtida uma radiografia panorâmica, revelando lesão radiopaca lobular, difusa e irregular. Com base nos aspectos clínicos e histopatológicos, o diagnóstico foi de DCOF associada com osteomielite secundária.

Conclusão: esse relato reforça a necessidade de uma avaliação precisa dos aspectos clínicos, radiográficos e histopatológicos para o diagnóstico e seleção correta de tratamento em casos de lesões combinadas.

Palavras-chave: Displasia cemento-óssea florida; osteomielite

\author{
Cyntia Helena Pereira de Carvalho a \\ Emeline das Neves de Araújo Lima ${ }^{a}$ \\ Joabe dos Santos Pereira a \\ Ana Miryam Costa de Medeiros a \\ Éricka Janine Dantas da Silveira a
}

a Department of Oral Pathology, Federal University of Rio Grande do Norte, Natal, RN, Brazil
Correspondence:

Éricka Janine Dantas da Silveira

Departamento de Odontologia - UFRN

Programa de Pós-Graduação em Patologia Oral

Av. Senador Salgado Filho, 1787 - Lagoa Nova

Natal, RN - Brazil

59056-000

Email: ericka_janine@yahoo.com.br

Received: September 14, 201

Accepted: April 11, 2012

Conflict of Interests: The authors state that there are no financial and personal conflicts of interest that could have inappropriately influenced their work.

Copyright: (c) 2011 Carvalho et al.; licensee EDIPUCRS. This is an Open Access article distributed under the terms of the Creative Commons AttributionNoncommercial-No Derivative Works 3.0 Unported License. 


\section{Introduction}

Fibro-osseous lesions are a group of bone disorders in which normal bone is replaced by fibrous connective tissue containing abnormal bone or cementum $(1,2)$. The World Health Organization (3) workshop group on head and neck tumours has classified osseous dysplasia (OD) into 4 subtypes based upon the extent and radiographic appearances: periapical osseous dysplasia in the anterior mandible, focal osseous dysplasia or focal cemento-osseous dysplasia in a posterior region of the jaws, florid cementoosseous dysplasia (FCOD), involving many quadrants of the jaws and familial gigantiform cementoma (FGC) (4). True FGC with familial history is extremely rare and, although cases with a familial pattern are reported in a few publications, sporadic cases have been seen without a family history. The term gigantiform cementoma has been used interchangeably with designations of other fibro-osseous entities, yet its application should be restricted by defined criteria for an autosomal dominant condition affecting the maxillae (5).

FCOD is a benign, non-neoplastic lesion and very rare condition in the jaws, most commonly seen in middle-aged black women, although it also may occur in Caucasians and Asians $(6,7)$. The authors use several terminologies, such as multiple enostoses, multiple cemento-ossifying fibromas, multiple periapical osteofibromatosis, florid cementoosseous dysplasia and gigantiform cementoma. Thereby, these nomenclatures of FCOD and other bone diseases are confusing in the literature $(8,9)$.

Clinically, these lesions are generally asymptomatic and may present as incidental radiological findings. Radiographically, FCOD appears as dense, lobulated masses, often symmetrically located in various regions of the jaws (7). Symptoms such as dull pain or drainage are almost always associated with exposure of sclerotic calcified masses in the oral cavity, i.e., secondary osteomyelitis (8). Histologically, these lesions are composed of anastomosed trabecular bone and layers of cementum-like calcifications soaked in a fibroblastic matrix (6).

Management of FCOD may be difficult and, in some cases, can be unsatisfactory. The disease may persist for indefinite periods of time without causing any symptoms (9). For the asymptomatic patient, the best management consists of regular examinations with prophylaxis and reinforcement of good home hygiene care to control periodontal disease and prevent tooth loss (10). In some cases, biopsy or elective extraction of teeth should be avoided. On the other hand, these procedures are necessary in cases of infection associated with a sequestration process (11).

In this manuscript, we describe the case of a patient who was diagnosed with FCOD associated with secondary osteomyelitis, who has been under follow-up for two years. Furthermore, we discuss the clinical and radiographic findings and differential diagnosis of this lesion and reinforce the importance of clinical and radiographies aspects for its correct diagnosis and follow-up.

\section{Case report}

A female, 69 years old, black patient was referred to the Oral Diagnosis Service, Federal University of Rio Grande do Norte (UFRN) / Natal-RN, Brazil, in September 2008, with a complaint of itching and pain in posterior left mandibular region. The patient was a smoker and her biochemical tests showed diabetes. Extraoral examination did not show any facial swelling or tenderness. Intraoral examination revealed many dental roots in the mandible and a partially edentulous area in the posterior left mandibular region. In this area, there was a yellowish hard mass, suggesting a sequestration process. A panoramic radiograph showed diffuse, lobular, irregularly shaped radiopacities or "cotton wool" appearance throughout the alveolar process of both quadrants, in both the maxilla and the mandible (Fig. 1). A periapical radiograph did not show other different features. Biochemical analysis of serum alkaline phosphatase, calcium and phosphorus were $45 \mathrm{U} / \mathrm{L} ; 9,4 \mathrm{mg} / \mathrm{dL}$ and $3,5 \mathrm{mg} / \mathrm{dL}$ respectively, being within the normal range, which are 39-117 U/L; 8,8-10,6 mg/dL and $2,5-4,8 \mathrm{mg} / \mathrm{dL}$ respectively, according to the protocols used. These tests were performed to make the differential diagnosis with Paget's disease, which shows results abnormally elevated. The clinical diagnosis was florid cemento-osseous dysplasia with an associated region of osteomyelitis.

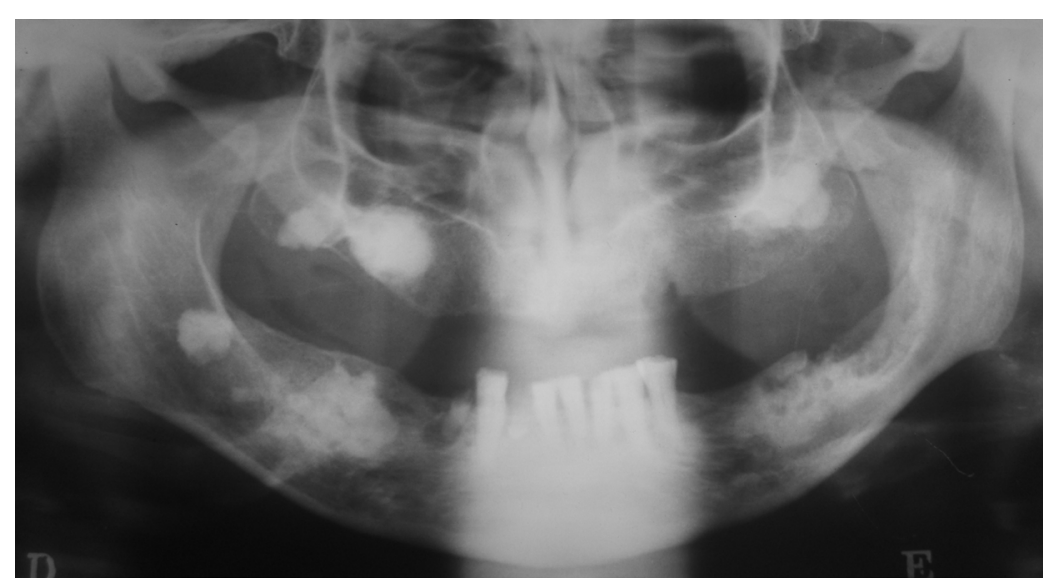

Fig. 1. Panoramic radiograph revealing diffuse, lobular, irregularly shaped radiopacities or "cotton wool" appearance throughout the alveolar process of both quadrants, in maxilla and mandible. 
For treatment purposes, the patient underwent hematological exams: complete blood count, fasting glucose, bleeding time and coagulation profile, which were all normal. Then, she received antibiotics to treat acute pain and suppuration. A surgical therapy was selected with removal of bone sequestrum. Biopsy of the sequestration process revealed fragments of bone tissue with irregular trabeculae and an amorphous granular material, with basophilic or eosinophilic color, compatible with necrotic tissue. Bone gaps were mostly empty, and there was presence of fibrous connective tissue between the trabeculae, showing moderately vascularization. In accordance with these findings, the histopathological diagnostic was necrotic bone tissue compatible with osseous sequestration (Fig. 2). Two years after surgery, the patient returned for followup exhibiting healing of the wound. A new panoramic radiograph exam for control purposes did not show any different findings.

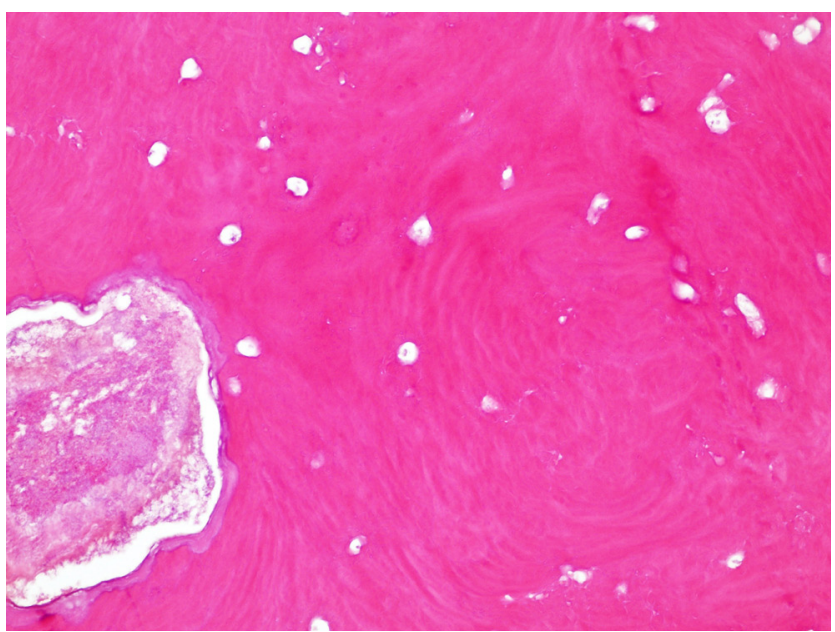

Fig. 2. Photomicrograph of the bone sequestrum showing fragments of bone tissue with empty osteoplasts and amorphous granular material, with basophilic color, compatible with necrotic tissue.

\section{Discussion}

The term florid cemento-osseous dysplasia (FCOD) has been proposed in the third edition of World Health Organisation's (WHO) "Word Health Organization Classification of Tumours / Pathology and Genetics of Head and Neck Tumours" (3). This condition was first described by Melrose et al. in 1976 (12) and has been interpreted as a dysplastic lesion or developmental anomaly arising in tooth-bearing areas.

This disorder is unusual and there are only 21 cases reported in the English literature in the last 10 years. It is strictly located in tooth-bearing areas and is not associated with any other skeletal disease (13). It may emerge as the result of progressive alveolar atrophy under a denture or after extraction of teeth in an affected area (10). However, its etiopathogenesis is not clear. Waldron (4) proposed that reactive or dysplastic changes in the periodontal ligament might be a cause for this disease. It may also be familial with an autosomal dominant inheritance pattern, but there are only few examples in the literature in which the familial pattern has been confirmed (7). Here, we present a case of patient who was diagnosed with FCOD associated with secondary osteomyelitis on the basis of clinical and radiographic findings that was not related to familial aspects.

In most instances, the disease affects the mandible bilaterally and may or may not show concomitant maxillary involvement (2). Most of the patients with FCOD are more than 45 years old, although it has also been reported in younger patients. Black females are more affected, but other ethnic groups may be affected. FCOD is usually asymptomatic and symmetrically distributed, as seen in the present case, but the patient was complaining of itching and pain in the posterior left mandibular region, probably because of the presence of bone sequestrum.

"Florid cemento-osseous dysplasia" is a histopathological term, but diagnosis can be decided by clinical and radiographic findings. These lesions exhibit a sclerotic appearance similar to that of other lesions in conventional radiographs. Paget's disease of the bone may have a cotton-wool appearance. However, this disease affects the bone of the entire mandible and shows loss of lamina dura, whereas FCOD is centered above the inferior alveolar canal. Paget's disease is often polyostotic, involving other bones such as spine, femur, skull, pelvis and sternum and produces biochemical serum changes, such as elevated alkaline phosphate levels (10). No biochemical alterations and other bone involvement were found in the case reported. In this case, the panoramic radiograph showed diffuse, lobular, irregularly shaped radiopacities or "cotton wool" appearance throughout the alveolar process of both quadrants in the maxilla and in the mandible.

Another disease that may resemble the FCOD is chronic diffuse sclerosing osteomyelitis (CDSO) (7). It appears as a single, poorly delineated opaque segment of the mandible (13), whereas FCOD is seen as multiple round or lobulated opaque masses. CDSO involves the body of the mandible from the alveolus to the inferior border and may extend into the ramus. In addition, FCOD is frequently associated with black women, while CDSO is seen predominantly in adult Caucasian men. In our case, the patient developed osteomyelitis associated with FCOD. Singer et al. (15) reported a case of a patient who presented FCOD with an overlying CDSO. They found unique characteristics to each process that allowed them to establish the differential diagnosis.

Bacterial infection is suggested to be a possible cause for this infection, but any general debilitating condition predispose osteomyelitis, such as chronic systemic diseases, disorders and states of immunosuppression associated with decreased vascularization of the bones, tobacco use, intravenous drug and alcoholism (16). The literature reports 
a strong association between diabetes and osteomyelitis, especially in the feet.

Histopathologically, it is characterized by a benign fibroosseous lesion that must be differentiated from other similar pathologies such as fibrous dysplasia, ossifying fibroma, Paget's disease and sclerosing osteomyelitis on the basis of combined clinical, radiographic, and histological features (2). These lesions are characterized by replacement of bone by connective tissue matrix, which displays varying degrees of mineralization with shapes of woven bone or cementumlike round basophilic acellular structures. The affected area undergoes changes in vascular irrigation within bone, leading to the formation of cementum-like structures (15). Here, the biopsy of the sequestration process revealed fragments of bone tissue with irregular trabeculae and an amorphous granular material with basophilic or eosinophilic color, compatible with necrotic tissue. Bone gaps were mostly empty, and fibrous connective tissue was present between the trabeculae, showing moderately vascularization. Thus, the histopathological diagnosis was necrotic bone tissue compatible with osseous sequestration.

Once the diagnosis is established in an asymptomatic patient, under normal circumstances there is no need for further treatment. The patient should be examined regularly in follow-up and recall appointments for prophylaxis and reinforcement of good home hygiene care to control periodontal disease and prevent tooth loss. In the absence of clinical signs, re-evaluation with panoramic or CT imaging every 2 or 3 years is adequate. Management of the symptomatic patient is more difficult because there is chronic inflammation and infection developing within densely mineralized tissue. In general, antibiotics are not effective in FCOD because of their poor tissue diffusion.

In some cases biopsy increases the risk for infection or may cause jaw fractures (10). Management of these conditions involves clinical-radiographic follow-up. Endodontic therapy should not be done before a definitive diagnosis is obtained, especially when it is based solely on radiographic findings without other signs and symptoms (7).

Our report reinforces the need for accurate assessment of clinical and radiographic aspects for the correct diagnosis and treatment plan for FCOD. In this case, the patient underwent conservative treatment because of the complexity of her situation: a fibro-osseous lesion associated with infection in a diabetic patient. During the follow-up of two years, the patient has shown good health conditions without major changes in the jaw, which highlights the effectiveness of the treatment and the need of long-term monitoring, especially in cases of associated lesions.

\section{Statement of Informed Consent}

Informed consent has been obtained from the patient for publication of this article. Review. Head and Neck Pathol 2008;2:177-202.

3. Barnes L, Eveson JW, Reichart P, Sidranski D, editors. Word Health Organization Classification of Tumours. Pathology and genetics of health and neck tumours. IARC Press: Lyon;2005.

4. Waldron CA. Fibro-osseous lesions of the jaws. J Oral Maxillofac Surg 1993;51:828-35.

5. Shah S, Huh KH, Yi WJ, Heo MS, Lee SS, Choi SC. Follow-up CT findings of recurrent familial gigantiform cementoma of a female child. Skeletal Radiol 2012;41:341-6.

6. Dağistan S, Tozoğlu Ü, Göregen M, Çakur B. Florid cemento-osseous dysplasia: A case report. Med Oral Patol Oral Cir Bucal 2007;12:348-50.

7. Gonçalves M, Píspico R, Alves FA, Lugão CEB, Gonçalves A. Clinical, radiographic, biochemical and histological findings of florid cemento-osseous dysplasia and report of a case. Braz Dent J 2005; 16:247-50.

8. Jankovski M. Florid cemento-osseous dysplasia: a systematic review. Dentomaxillofac Radiol 2003;32:141-9.

9. Pitak-Arnnop P, Dhanuthai K, Chaine A, Bertrand J-C, Bertolus C. Florid osseous dysplasia: Report of a case presenting acute cellulitis. Med Oral Patol Oral Cir Bucal 2009;1 4:461-4.

10. Gündüs K, Avsever H, Karaçayli Ü, Şenel B, Pişkin B. Florid cemento-osseous dysplasia: a case report. Braz Dent J 2009;20:347-50.

11. Park IW, Choi HM, Park YW, Kim SM, Kim JH, Huh JY et al. Calcifying tissue of florid cemento-osseous dysplasia easily involving chronic diffuse sclerosing osteomyelitis. Basic Appl Pathol 2008;1:107-9.

12. Melrose RJ, Abrams AM, Mills BG. Florid osseous dysplasia: a clinical-pathology study of thrirty four cases. Oral Surg Oral Med Oral Pathol 1976;41:62-82.

13. Jerjes W, Banu B, Swinson B, Hopper C. Florid cemento-osseous dysplasia in a young Indian woman. A case report. Br Dent J 2005;198:477-8.

14. Spazzin AO. Osteomielite dos maxilares. Rev Med HSVP 2004;16:23-7.

15. Singer SR, Mupparapu M, Rinaggio J. Floride cemento-osseous dysplasia and chronic diffuse osteomyelitis: Report of a simultaneous presentation and review of the literature. J Am Dent Assoc 2005; 136:927-31.

16. Hino S, Murase R, Terakado N, Shintane S, Hamakawa H. Response of diffuse sclerosing osteomyelitis of the mandible to alendronate: follow-up study by $99 \mathrm{mT}$ scintigraphy. Int J Oral Maxillofac Surg 2005;34:576-8. 